\title{
UNIVERSITY OF WASHINGTON QUATERNARY ISOTOPE LABORATORY RETROSPECTIVE
}

\author{
Paula J Reimer ${ }^{1 *}$ (D) Thomas F Braziunas ${ }^{2}$ - Thomas A Brown ${ }^{3} \cdot$ Robert L Burk $^{4}$ •

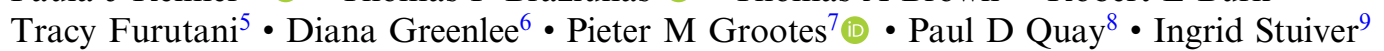 \\ ${ }^{1}$ 14CHRONO Centre for Climate, the Environment and Chronology, Queen's University Belfast, Belfast BT7 1NN, \\ UK \\ ${ }^{2}$ North Seattle College (retired emeritus), 9600 College Way N, Seattle, WA 98103, USA \\ ${ }^{3}$ Center for Accelerator Mass Spectrometry, Lawrence Livermore National Laboratory, 7000 East Avenue, Livermore, \\ CA 94550, USA \\ ${ }^{4}$ Burk Geo Consult (retired), Seattle, WA, USA \\ ${ }^{5}$ North Seattle College, 9600 College Way N, Seattle, WA 98103, USA \\ ${ }^{6}$ Poverty Point World Heritage Site, Archaeological Curatorial Facility, 146 Poverty Point Drive, Pioneer, LA 71266, \\ USA \\ ${ }^{7}$ Ecosystem Research Institute, Christian Albrechts University Kiel, DE 24118 Kiel, Germany \\ ${ }^{8}$ College of the Environment, University of Washington, 1492 NE Boat St., Seattle, WA 98105, USA \\ ${ }^{9}$ La Jolla Institute for Immunology, 9420 Athena Circle, La Jolla, CA 92037, USA
}

ABSTRACT. The Quaternary Isotope Laboratory (QIL) at the University of Washington was launched in 1969 and directed by Minze Stuiver until his retirement in 1998. Here we review some of the scientific work undertaken in the QIL and the memories of some of Minze's former students and colleagues.

KEYWORDS: isotopes, Minze Stuiver, Quaternary Isotope Lab, radiocarbon, tree rings.

\section{INTRODUCTION}

Shortly after the Quaternary Research Center was established at the University of Washington in 1969, Minze Stuiver was recruited from Yale to set up the Quaternary Isotope Laboratory (QIL). Minze's radiocarbon background with Hessel de Vries in Groningen and his research at Yale made him uniquely qualified to design and construct a prime radiocarbon facility. One facility focus would be the high-precision measurement of natural fluctuations in atmospheric ${ }^{14} \mathrm{C}$ levels using tree rings, a topic actively pursued by Minze in Yale. The lab was to be constructed in the basement of the new underground building with the radiocarbon counters in a room dug $11 \mathrm{~m}$ deep into the glacial till to shield the $\beta$-decay counters from cosmic radiation and thus reduce and stabilize their background (Stuiver 2016).

To minimize radioactivity of the counter shielding, Minze acquired lead bricks from several mines and tested their radiation levels. Together with the newly hired technician, Phillip Wilkinson, he moved 50 tons of the lowest radioactivity lead bricks down into the counting room. To support the lead on top of the counters, pre-atomic bomb steel and copper-nickel alloy sheets were acquired from old battleships being dismantled at the naval station in Bremerton. Lead ingots, recovered from a ship that sank in the North Sea in the 1600s, were obtained from Groningen. This lead provided special low-radioactivity shielding directly around the counters.

Using his earlier designs Minze built several counters with a high effective volume and low background, using ultrapure copper tubes, which he polished inside, for low residual radioactivity. High-voltage supplies provided the electric field to attract the electrons produced in $\beta$-decay and give gas multiplication in the proportional counters. A ring of anti-coincidence counters surrounded the sample counters in order to subtract counts

*Corresponding author. Email: p.j.reimer@qub.ac.uk 
caused by cosmic radiation. The QIL counter setup also included a counter given by $\mathrm{H}$. Göte Östlund, Miami partner in the GEOSECS project. The counters were controlled by a hefty Wang desktop computer programmed by Stephen Robinson to collect the number of counts and calculate the radiocarbon ages. Systems for the production of $\mathrm{CO}_{2}$ by combustion and by extraction from carbonates or water as well as for the purification of this $\mathrm{CO}_{2}$ for proportional gas counting were constructed from glass. Fortunately, Minze was accomplished at glassblowing and the laboratory was soon gleaming with tubes and bulbs.

The QIL, also known as the Geosecs ${ }^{14}$ C Laboratory, was completed in May 1973 (Stuiver and Robinson 1974). After successful completion of cross-checks between the Universities of Washington and Miami (Stuiver et al. 1974), some of the first radiocarbon measurements were on $\mathrm{CO}_{2}$ from ocean water as part of GEOSECS (Geochemical Ocean Section Study). Another early lab study involved potassium-argon dating of young lava flows (Porter et al. 1977), also aimed at establishing an overlap between the radiocarbon and potassium-argon dating methods. The overlap was accomplished, but the uncertainty for the old radiocarbon and extremely young potassium-argon results was large. A hot-wire system for the thermal diffusion enrichment of radiocarbon was constructed, based on the Amsterdam design developed together with Hessel de Vries in Groningen. This system concentrates radiocarbon as ${ }^{14} \mathrm{CO}$ by about a factor ten to allow the dating of samples back to 75,000 BP, providing the oldest radiocarbon ages (Stuiver et al. 1978).

With the radiocarbon lab, the GEOSECS program, and tree-ring ${ }^{14} \mathrm{C}$ calibration studies up and running, Minze brought in researchers, postdocs, students and technicians to branch out into many more areas of Quaternary research including stable isotopic carbon tracer analyses in oceanography, limnology and vegetation, and oxygen-isotope records in ice cores and vegetation. The growing data sets, resulting from the diverse measuring projects, provided the input for global carbon cycle modeling of long-term solar modulation of ${ }^{14} \mathrm{C}$ production, ocean circulation, biosphere changes, fossil fuel use, and climate. Minze had many scientific ideas and generously shared them with his collaborators.

Despite the great variation in individual projects, QIL membership involved constant interaction, and the lab operated as a cohesive team. Each QIL person has their own memories of Minze. Here, a few of us reminisce a little about those days when the lab produced so much good science from the committed efforts and friendships of many colleagues working together.

The memories of Seattle and QIL for Pieter Grootes (researcher 1977-1994) start with Minze and Minze's wife, Anneke, welcoming Piet and his wife, Grada, at Sea-Tac Airport in late spring 1977, hosting them for two weeks in their nice Bellevue home among the high trees and helping them find an apartment. To a Dutchman, those trees were really big! Trees, of course, played a major role in Minze's research, going back to Minze's days with de Vries in Groningen and a key 1958 paper on the variation in concentration of radiocarbon with time and location on Earth. Minze started his own dendrochronology project for which the American West Coast provided ample suitable trees.

Paula Reimer (technician/programmer/student 1977-1998) remembers Minze as also being a keen gardener. Once, while cleaning out the cold storage room, she found an unlabeled paper bag with dark lumps in it. She took this to Minze who was surprised to see the dahlia tubers he had stored there when he went on sabbatical to Heidelberg years earlier. He had been very proud of his dahlias. 
Bob Burk (student/researcher 1977-1981) recalls Minze's training on glassblowing in order for Bob to help build QIL's incredible maze of sample purification lines (in a lab too costly to build today). During Bob's first days in the lab, Minze told him to take a full-length piece of glass tubing and break it into small, say $4 \mathrm{~cm}$, pieces and put the pieces back together again. Bob says: "Having never worked with glass you can imagine how horrible my work was!!! After some rebuke for my work, Minze sat down at the table with the glass torch and showed me how to work with glass. I kept at it and when the professional glass blower from Physics came over to work, I always watched. Soon I was doing much of the routine glass blowing in the lab and only called the pro when I was in trouble or the jobs were complex. The long glass line that went all the way to the counting room downstairs was my showpiece-we called it the Trans QRC Pipeline!!!”

Bob recalls, when a stopcock was low on grease, Minze liked to tell the wartime story of Holland when grease was not available and people in the lab used earwax for stopcock grease (although such was never the case in QIL). Bob also remembers Minze's frequent exclamation of "This is not science" when he would read a questionable "scientific" article. He said it so much that QIL lab members had a rubber stamp made with a red ink pad so he could mark such articles and papers with "this is not science." To test it out, Minze promptly stamped it on a copy of Bob's thesis! After Bob finished his PhD, Minze was also fond of saying "when Bob came to the lab he was a geologist, now he is an improved geologist.",

After thesis work, Bob was asked to collect tree sections from a wide variety of locations for measurement of carbon isotopes as a guide to the transfer of biospheric carbon to the atmosphere (Stuiver et al. 1984). Bob carried a chainsaw into southern Chile including Tierra del Fuego and Torres del Paine National Park and searched for windswept trees away from industrial pollution. Bob considers this to be a fabulous assignment by Minze for a young doctorate!

Cutting decadal and single-year tree-ring samples, turning them to powder (starting with a kitchen blender which died from overwork very soon and was replaced by a proper Wiley Mill) and then into pure white $\alpha$-cellulose kept Phil and Paula busy. The counters, in their deep-underground room, produced radiocarbon calibration data from these samples with unprecedented precision of $<0.2 \%$. Over the years, the QL tree-ring series stretched from Kodiak island, Alaska, to southern Chile, complemented by German and Irish Oaks. Comparisons with Irish oak measurements from the Belfast laboratory showed very good agreement even though different tree species and different counting methods were used. Additional intercomparisons with Heidelberg helped to verify the German oak chronology.

From these results the international radiocarbon calibration grew as well as the programming and carbon cycle modelling to extract regional and global environmental information from the wiggly curves. Paula recalls that Minze returned from the 12th International Radiocarbon Conference, Trondheim, in 1985 and instructed her to build a calibration curve from the recommended tree-ring data, as well as to write a computer program for radiocarbon calibration (Stuiver 1986; Stuiver and Reimer 1986). "I was unaware that there had been many previous efforts to construct calibration curves, some very statistically sophisticated, whereas my methods were rather crude in comparison. But the tree-ring data had improved so much that the 1986 atmospheric curve was a success." Tom Braziunas was responsible for using an ocean-atmosphere box model to produce a calibration curve for marine 
samples (Stuiver et al. 1986). Paula notes that some of this remarkable tree slab collection is still preserved at a University of Washington Burke Museum storage facility and can still contribute to future projects.

Paul Quay (researcher 1977-1984) shares this memory: “After I had been working with Minze for about a couple months as a brand new overconfident postdoc, he called me into his office. He said calmly 'Paul, when we talk you have to let me finish my sentences before interrupting. You need to listen to what people have to say and learn from it.' As a born-and-bred New Yorker I didn't even realize I was interrupting him. It was a lesson gently conveyed by Minze that I'm still trying to follow 40 years later."

Tom Braziunas (student/researcher 1982-1998) remembers the stability of daily life in a basement lab removed from surface distractions and led by a meticulous and alwaysaccessible scientist who spent nearly every day at his desk double-checking measurements, writing papers and grant proposals, and answering calls and emails from colleagues. Minze was a vintage scientist, unaffected by his recognized stature, with pencil-and-paper at hand, his office phone lacking an answering machine, his primary "vita" consisting only of a single page.

Tom also remembers Minze's good-natured nudging that computer models (like the global carbon cycle ones Tom and others worked with) would always come and go but "a good dataset (like the radiocarbon calibration measurements) is forever!" Those computer models, by the way, initially took a day to run a high-resolution Holocene-length global isotopic carbon cycle. Bob adds in that, after running models all night, the initial HP-9825 computer would be hot to the touch! Computational power transitioned such that the same model runs took just a few minutes to run as the digital world took shape in the later 1980s.

Minze's students and colleagues can attest that, as an educator, Minze was a boundless classroom resource, teaching without notes and able to address every question, regardless of its depth and detail, in elegant and satisfying precision. Tom recalls the many times that a follow-up request in class for even greater detail would receive a response by Minze such as "are you sure you want to know more..." before he launched into even finer specifics and eventually first principles. Minze was a textbook!

Tom Brown (student 1987-1994) remembers coming to the University of Washington's Geophysics Program to join the UW Accelerator Mass Spectrometry group that was a combination of members of the QIL and the UW Nuclear Physics Laboratory-an interestingly inhomogeneous mix indeed. As radiocarbon became a central focus of his research, Tom benefited greatly from the support Minze provided to the ${ }^{14} \mathrm{C}$ AMS effort and from the ability to talk directly to one of the preeminent radiocarbon scientists. In one instance, Tom remembers that after a discussion with Minze concerning AMS's small sample capabilities and the possibility of monthly-resolution ${ }^{14} \mathrm{C}$ measurements on banded coral samples, Minze generously offered access to the essentially irreplaceable sets of Galapagos corals that remained from earlier ${ }^{13} \mathrm{C}$ work. Minze decisively cleared away the most daunting obstacle to the research!

Tom also remembers his multiple discussions with Minze tied to a key ${ }^{14} \mathrm{C}$ data-reporting paper written one sunny hour at a picnic table by Minze and Henry Polach of the Australian National University (Stuiver and Polach 1977). After many years, Tom continues to find that he advises researchers new to radiocarbon to go to that much-cited paper with its density of information, 
keeping in mind that every word seems to have been chosen with a particular, specific intent. Tom remembers too the twinkle in Minze's eyes during conversations when he found something humorously ironic, and that, on occasion, the humorously ironic thing was something Tom had just said without seeing the irony in his words. Tom learned to pay attention to those looks.

Tracy Furutani (student 1989-1994) is deeply grateful to Minze for taking him on as one of his last graduate students despite working on a dissertation project not based on carbon or oxygen isotopes and for which the lab had no resources. Regarding Minze's lecture style, Tracy remembers it as uniquely soft-spoken and often tailing off into inaudibility. Minze would occasionally give a brief smile at a small joke he had made and even though the joke was not heard, Tracy says he "knew Minze had cracked one, because he would sometimes add a soft 'ho, ho, ho' laugh to the smile." The positive effects of these amiable discourses on students may seem trivial, as Tracy notes, "but they remain etched in my memory, long after all the equations and inferences are gone."

Diana Greenlee (student 1992-1998) remembers Minze's kindness in supporting her Archaeology Program research in the lab and as a member of her $\mathrm{PhD}$ committee. Diana appreciates that "Minze was always ready with a smile and a "thumbs up." Although originally her stable carbon isotope samples were to run on the antiquated Nuclide 6-60 RMS mass spectrometer, when sufficient sweat and tears had been shed trying to get it leak-free, Minze "relented" and allowed her to use the automated Micromass. For that, she will be forever grateful. Etched in Diana's memory as well is the time during her oral exam when Minze asked her to calculate the effect of some percentage of dead carbon on a radiocarbon sample of a particular age. She notes that "this calculation had been wellcovered in class, homework, and tests, but trying to do it on the blackboard, with no calculator, after nearly two hours of grilling in this tiny, stifling, exam room, caused a brain malfunction. I was a deer in the headlights. Minze seemed surprised by this and calmly provided some much-needed assistance, along with the affirming statement that 'I know you know how to do this.",

Minze was deeply involved in his projects and, where possible, went in the field himself to take samples and so better understand their context. Piet remembers that joining him for sampling was a nice way to get to know some of the side roads and back country of Washington State in the company of palynologists Cal and Linda Heusser from New York University. Minze accompanied University of Maine's George Denton (a former Yale student) to Taylor Valley, Dry Valleys, Antarctica in the mid-1970s to develop radiocarbon dating in barren Antarctica. Lacustrine algae grow in abundance in small ice-marginal ponds that occur all along the Transantarctic Mountains. Ice advances through the ponds mixed morainal material with datable lacustrine algae. As George reports, dating them was successful and, with much sieving to concentrate the algae, the QIL efforts yielded a wonderful chronology of fluctuations of Antarctic glaciers. Minze, as Antarctic Explorer, left his name in Taylor Valley when the Advisory Committee on Antarctic Names named a high hanging valley at

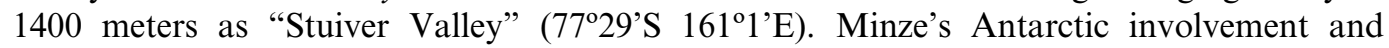
broad scientific contacts also brought oxygen isotope ice core research to the QIL in a collaboration with Lonnie Thompson on the Peruvian Quelccaya ice core and with the GISP2 and Taylor Dome ice core projects (Stuiver et al. 1997). 
Living invertebrates and recently deceased Antarctic animals (including from the Scott polar expedition) yielded surprisingly high radiocarbon ages, connected with high local marine reservoir ages, another topic of Minze's research, whose Antarctic work with University of Maine's George Denton and others is referenced in a compilation of Antarctic isotopic dates (Stuiver and Braziunas 1985). Drying seal and penguin tissue samples in the oven in QIL, however, turned out to not be a very good idea. Minze's doctoral work at the University of Groningen was done with de Vries on the "The Biophysics of the Sense of Smell" and the Antarctic sample preparation technique turned out, ironically, to be a definite offense to "the sense of smell"!

Ironically too, in a lab focused in part on measuring the advancement of time, the emphasis was sometimes to "slow down." With a focus on quality over quantity, dozens of large glass flasks lined the walls patiently waiting the forty days necessary for decay to remove radon from the purified carbon dioxide prior to counting. Minze believed in letting time provide a simple approach toward refining sample preparation processes. That throng of glass flasks, along with the multitude of glass purification mazes and the spiral metal staircase leading down to the subterranean counting room (the "cave"), all provided for an impressive tour for many classes of geology students and other visitors who reacted with awe to QIL's captivating "this is a real lab!" experience. A lot of liquid nitrogen was used in the lab, and a favorite demonstration for younger students was to freeze rubber tubing and then crack it into pieces.

Minze's family (Anneke and daughters, Ingrid and Yolande) also contributed time and energy toward keeping QIL's samples moving along, including filling counters on weekends. Ingrid recalls a high school summer nearly losing her hearing while sieving glacial sediment for algae on the geology loading dock. Ingrid learned to solder copper wire at an early age (with scars on her legs from dripping hot metal to prove it!). Such familial lab skills started when the Stuivers were at Yale, Ingrid noting that "before OSHA, they still let children into labs in the 1960s!" Her glassblowing expertise continues today as she has become a budding glass artist as one of her many avocations (including scuba diving among tiger sharks in Fiji, perhaps an outcome of lots of family time watching Jacque Cousteau on TV!). Her father proudly admired the creative skills of the second glassblower in the family.

Minze was at the forefront of science and we QIL members were lucky to be in the front row on many collegial gatherings that included renowned visitors, whether in the lab itself or during evening dinners at the Stuiver residence. Some of us recall seeing others asleep on Minze's and Anneke's couch after long talks about science until midnight! Such conversations were occurring prior to QIL as well. Ingrid recalls hearing from her father about a telling one that happened in the 1960s when Minze, Roger Revelle and Dave Keeling were chatting together about their insights into the global carbon cycle and the anthropogenic effects they saw happening even back then. They were weighing how much to pursue widely publishing an "alarm" based on their germinal research and foresights. However, they decided that, as human nature would have it, the human population would inevitably just be "conducting the global experiment" of atmospheric and climate change no matter what was said by any scientist at that time. Ingrid recalls the exact quote as, "Well, the experiment will be done." Perhaps we have all been "asleep on the couch" too long!

Such was life in the University of Washington's QIL, housed deep down in the bowels of the Quaternary Research Center (until QIL's closure at Minze's retirement in 1998) and identified 
one time with a headlined misnomer in the campus paper as the college's "underground dating service." Minze's interest in the world around us and his tendency to get to the bottom, that is physics, of things provided a stimulating environment for all of us. QIL's research focus on climate was ironic since, as we were equilibrating invisible gases, counting charged particles, and measuring microscopic atoms, the seasons passed by us without notice except for an occasional thunderclap! However, as members of a harmonious and productive team under Minze's leadership, we will cherish those days as timeless ones.

\section{REFERENCES}

Porter SC, Stuiver M, Yang IC. 1977. Chronology of Hawaiian glaciations. Science 195 (4273):61-63.

Stuiver M. 1986. Editorial comment. Radiocarbon 28(2B):ii.

Stuiver M. 2016. Tales of war and science: a memoir by Minze Stuiver, Ph.D. Unpublished.

Stuiver M, Braziunas TF. 1985. Compilation of isotopic dates from Antarctica. Radiocarbon 27(2A):117-304.

Stuiver M, Braziunas TF, Grootes PM, Zielinski GA. 1997. Is there evidence for solar forcing of climate in the GISP2 oxygen isotope record? Quaternary Research 48:259-266.

Stuiver M, Burk RL, Quay PD. $1984 .{ }^{13} \mathrm{C} /{ }^{12} \mathrm{C}$ ratios in tree rings and the transfer of biospheric carbon to the atmosphere. Journal of Geophysical Research: Atmospheres 89:11731-11748.

Stuiver M, Heusser CJ, Yang IC. 1978. NorthAmerican glacial history extended to 75,000 years ago. Science 200(4337):16-21.
Stuiver M, Pearson GW, Braziunas T. 1986. Radiocarbon age calibration of marine samples back to 9000 cal yr BP. Radiocarbon 28(2B):980-1021.

Stuiver M, Polach HA. 1977. Discussion: reporting of ${ }^{14} \mathrm{C}$ data. Radiocarbon 19(3):355-363.

Stuiver M, Reimer PJ. 1986. A computer program for radiocarbon age calibration. Radiocarbon 28(2B):1022-1030.

Stuiver M, Robinson SW. 1974. University of Washington Geosecs North Atlantic carbon-14 results. Earth and Planetary Science Letters 23:87-90.

Stuiver M, Robinson SW, Östlund HG, Dorsey HG. 1974. Carbon-14 calibration between the University of Washington and the University of Miami GEOSECS laboratories. Earth and Planetary Science Letters 23:65-68. 